\title{
An audit on the prescription and administration of ECT at NIMH, Sri Lanka
}

\author{
DMA Dahanayake, YM Rohanachandra, ARK Dissanayake, H Gambheera
}

\section{Background}

Audits on the practice of electroconvulsive therapy (ECT) have shown deficiencies in meeting expected standards and have highlighted the auditing of ECT as being essential for quality improvement.

Aims

To evaluate the practice of ECT at the National Institute of Mental Health (NIMH) Colombo, against the guidelines of the Royal College of Psychiatrists, UK and the Royal Australian and New Zealand College of Psychiatrists.

\section{Methods}

An audit was carried out in a consecutive sample of 111 patients. Data was collected from the patients' clinical records using a specifically designed instrument, based on the guidelines.

\section{Results}

The mean age of the sample was 39.9 years and $44 \%$ were males. The most commonly noted diagnosis was schizophrenia (37\%) and failure to respond to first line treatment (33\%) was the most frequent indication (irrespective of diagnosis) for administration of ECT.

There were many inadequacies in the administration of ECT, including poor documentation of indication for ECT, inadequate monitoring of motor seizures, lack of adherence to recommended guidelines regarding modifications and poor maintenance of records. Only $50 \%$ of patients had developed a motor seizure of $>20$ seconds, and the average energy dose increment was $5 \%$ in subsequent ECTs. Post-ECT assessment was substandard in up to $78 \%$.

\section{Conclusion}

We recommend formulating institutional guidelines in Sri Lanka to improve the administration of ECT, followed by a continuation of the audit for reevaluation of the procedure of ECT.

Key words: ECT, audit, indications, administration

SL J Psychiatry 2015; 6(1): 22-25

\section{Introduction}

Electroconvulsive therapy (ECT) was introduced as a method of treatment for patients with psychiatric disorders by Cerletti and Binni in 1938 and its use spread rapidly; it was seen as the first effective, reliable and inexpensive treatment modality for major psychiatric disorders (1). This led to a period of indiscriminate use and misuse of ECT, particularly during the mid- $20^{\text {th }}$ century, resulting in ECT acquiring a bad reputation and adverse public perception (1). Early adverse effects experienced due to unmodified ECT, such as tongue bites, fractures and broken teeth caused by the induction of generalized seizures, made ECT a high risk procedure in the early days. However, after the introduction of general anaesthesia and muscle relaxants, those severe complications disappeared (1).

By 1940, ECT was beginning to be used in Sri Lanka (2) and an electrical treatment centre was opened at then Mental Hospital Angoda during this period (2). Initially, ECT was administered without general anaesthesia and later under anaesthesia administered by a trained medical officer. Initially the anaesthesia was limited to administration of thiopentone without use of muscle relaxant. Much progress has been made since those early days, and currently ECT is administered at NIMH with EEG monitoring, using a modern Thymetron machine at a specialised unit.

Hospital data show that 826 electroconvulsive treatments are administered monthly at NIMH on an average of 152 patients. However, many deficiencies have been observed in administration of ECT at NIMH. Similarly, even audits conducted internationally indicate inadequacies in techniques of administration of ECT and post-ECT assessment $(3,4)$. A study done in Sri Lanka has shown that informed consent was not taken in $70 \%$ of the patients and understanding of the treatment was poor in $75 \%$ of patients (5).

The objective of this study is to evaluate the practice of ECT at NIMH with reference to recommendations of current guidelines and accepted practices, with a view to improving the quality of service provided.

\section{Methodology}

An audit was carried out on a consecutive sample of 111 patients who received ECT at NIMH during March 2012. Data was extracted from the clinical records using a 
specially designed data extraction form. Audit standards were set according to the guidelines for ECT of the Royal College of Psychiatrists UK, the Royal Australian New Zealand College of Psychiatrists and the American Psychiatric Association (6-8). Where guidelines were not available, evidence based clinical practices relating to administration of ECT were used to develop audit criteria (9).

ECT practices were assessed in the following 8 domains; indications for ECT, obtaining consent, modification of drug regimens prior to ECT, energy dosing, monitoring of seizures, dose increments in subsequent ECT's, postECT assessment by the psychiatric team and the completion of the ECT form.

\section{Results}

Out of the 111 patients included in the sample, $56 \%$ were males. The mean age of the sample was 39.9 years. A majority (74.8\%) were involuntary admissions. In 76\%, there were no comorbid medical conditions. Bilateral electrode placement was used in all but one patient. The median number of ECTs given for a patient was 6 . On average, a patient received ECT thrice a week. In 29.7\% of patients, ECT was prescribed within 24 hours of admission.

The distribution of diagnoses of patients in the sample and the indications for giving ECT are shown in Table 1.

Although the ECT prescription form had a section for recording consent, informed consent was not obtained from any of the patients in the sample, irrespective of their admission status or capacity to give consent. In all cases, the course of ECT had been prescribed by a consultant psychiatrist.

The previous night's dose of benzodiazepine was not omitted in $61 \%$ and sodium valproate was not omitted nor was the dose adjusted in $42 \%$. Lithium carbonate was not omitted in $71 \%$. Stimulus dosing titration, stimulus dosing tables or other stimulus dosing methods such as the half-age method was not used in many cases and most patients (78\%) received an energy dose of $15-20 \%$, irrespective of their age, gender, seizure threshold or concurrent medication.

In all patients, the length of the motor seizure but not the cerebral seizure was monitored, despite the fact that EEG monitoring was available. The description of the seizure was vague (e.g., good fit, moderate fit or mild fit) in all cases. Stop-timers were not used in estimating the duration of the seizure. The average duration of a seizure was 16.1 seconds and in more than $50 \%$, the seizure duration was less than 20 seconds. In all patients in the sample, the energy dose was increased by $5 \%$ in subsequent ECTs, irrespective of the quality and duration of the previous seizure.

\begin{tabular}{|c|c|}
\hline Indication for ECT & $\begin{array}{l}\text { Proportion of } \\
\text { patients treated } \\
\text { with ECT: Percen- } \\
\text { tage (number) }\end{array}$ \\
\hline \multicolumn{2}{|l|}{ As first-line treatment: } \\
\hline $\begin{array}{l}\text { Severe depression (Recurrent } \\
\text { depressive disorder/ Bipolar } \\
\text { affective disorder) with } \\
\text { significant suicidal risk }\end{array}$ & $14.4 \%(16)$ \\
\hline $\begin{array}{l}\text { Severe depression (Recurrent } \\
\text { depressive disorder/ Bipolar } \\
\text { affective disorder) with } \\
\text { psychomotor retardation }\end{array}$ & $0.9 \%(1)$ \\
\hline $\begin{array}{l}\text { Severe depression (Recurrent } \\
\text { depressive disorder/ Bipolar } \\
\text { affective disorder) } \\
\text { with psychotic symptoms }\end{array}$ & $4.5 \%(5)$ \\
\hline Severe mania & $18 \%(20)$ \\
\hline Catatonic schizophrenia & $2.7 \%(3)$ \\
\hline Puerperal psychosis \& depression & $2.7 \%(3)$ \\
\hline \multicolumn{2}{|l|}{ As second-line treatment: } \\
\hline $\begin{array}{l}\text { Failure of first line treatment } \\
\text { (Schizophrenia/Recurrent } \\
\text { depressive disorder/Bipolar } \\
\text { affective disorder) }\end{array}$ & $33.3 \%(37)$ \\
\hline \multicolumn{2}{|l|}{ Other: } \\
\hline $\begin{array}{l}\text { As } 3^{\text {rd }} \text { or } 4^{\text {th }} \text { line treatment } \\
\text { in schizophrenia }\end{array}$ & $9.9 \%(11)$ \\
\hline Other/ Not mentioned & $13.5 \%(15)$ \\
\hline
\end{tabular}

Table 2. Distribution of diagnoses in the sample

\begin{tabular}{|l|l|}
\hline Diagnosis & $\begin{array}{l}\text { Percentage } \\
\text { (number) of } \\
\text { participants }\end{array}$ \\
\hline Schizophrenia & $36.90 \%(41)$ \\
\hline $\begin{array}{l}\text { Bipolar affective disorder - manic } \\
\text { episode }\end{array}$ & $30.60 \%(34)$ \\
\hline Recurrent depressive disorder & $18 \%(20)$ \\
\hline $\begin{array}{l}\text { Schizo-affective disorder - manic } \\
\text { episode }\end{array}$ & $4.50 \%(5)$ \\
\hline $\begin{array}{l}\text { Bipolar affective disorder - } \\
\text { depressive episode }\end{array}$ & $4.50 \%(5)$ \\
\hline Unipolar major depression & $1.80 \%(2)$ \\
\hline Other & $1.80 \%(2)$ \\
\hline Puerperal psychosis & $0.90 \%(1)$ \\
\hline $\begin{array}{l}\text { Bipolar affective disorder - mixed } \\
\text { episode }\end{array}$ & $0.90 \%(1)$ \\
\hline
\end{tabular}


Post-ECT cognitive assessment by the psychiatric team was unsatisfactory in a majority (57.7\%) of the patients when compared to the standards set by the Royal College of Psychiatrists (6). A medical officer or a registrar had assessed the patient for subjective complaints and cognitive side effects only in one fifth of the sample (21.1\%).

The ECT form was completed only in $78 \%$, with the main deficiencies being incomplete documentation of informed consent (100\%), indications for ECT (47.6\%), concurrent medications (15.8\%) and the details of previous course of ECT (100\%).

\section{Discussion}

ECT is recommended as a third or fourth line treatment for schizophrenia with the exception of catatonia and emergency situations (6). Yet schizophrenia was the commonest diagnosis among the patients who received ECT. However, data on distribution of various diagnoses among in-patients in the hospital is required before commenting on this finding, as the percentage of inpatients with a particular diagnosis receiving ECT was not calculated in our study. In $13.5 \%$ of the cases, the indication for ECT was not clearly mentioned.

Assessment of capacity to give consent for ECT among both voluntary ( $25 \%$ of the sample) and involuntary patients had not been carried out. ECT was administered to all patients in the study without informed consent irrespective of their capacity to consent. Furthermore, the current Mental Disease Ordinance does not have provisions for giving ECT without informed consent (10). If a patient does not have the capacity to give consent, the ethical principle of beneficence is adopted and the treating psychiatrist decides on treatment in the best interest of the patient (9). In such situations, seeking second opinion from another psychiatrist is a good practice. However, this was not observed in any of the patients in this sample.

Modifications of drug regimes, such as withholding sodium valproate and benzodiazepines, were not practiced as recommended in the guidelines (6-8). This may have contributed towards the reported inadequate seizure responses.

Unilateral administration had been used only in one patient out of 111 . This may have been due to unfamiliarity with this technique. A further matter of serious concern was the apparent arbitrary way of deciding the energy dose of initial ECT; the method of calculation of the dose was not described in the documents. Seizure threshold has not been assessed using stimulus dosing techniques as recommended, nor even methods such as half-age method for calculating seizure threshold had been used. This too may have contributed to the inadequate seizure duration in many patients. Monitoring of the motor seizure was also unsatisfactory. The inbuilt stop-timer, which starts once the current is cut-off, was not used. Instead, the wall clock was used and the recorded durations were not precise. Even though the ECT machines had facilities for EEG recording and easy titration of energy doses, these were not utilised.

When deciding energy for subsequent ECTs, increase in seizure threshold or the quality and duration of the previous seizure were not taken into consideration. Increasing the energy dose by $50 \%$ in order to achieve a satisfactory outcome was not carried out. It is recommended that an increase in dose should be decided based on several factors, including increase in seizure threshold after each ECT, concomitant medication that may affect seizure threshold and degree of cognitive side effects. However, these factors were not taken into consideration in calculating the dose.

Post ECT assessment by psychiatric team was unsatisfactory. More than half of the patients were not assessed as recommended within 12 hours post-ECT.

\section{Limitations}

This audit had certain limitations. It was conducted in a consecutive sample of patients, and was limited to those who received ECT in March 2012. The audit data is derived entirely from the patient records (bed head tickets) and the ECT forms; individual patients were not seen and concerned staff members were not interviewed. We did not directly observe the procedure of administering ECT or monitoring of seizures. Additionally, there were difficulties in formulating audit criteria due to lack of clear guidelines on some aspects. Therefore, some audit criteria may have seemed arbitrary.

\section{Conclusions}

Based on the findings of this audit, we recommend formulating institutional guidelines for NIMH that describe indications, modifications of drug regimens before ECT, and give recommendations for deciding energy and monitoring seizures, post-ECT assessment and maintenance of records. It is also worth exploring further why the ECT form was not accurately maintained, and what modifications may be required to facilitate better documentation. A key person should be appointed to monitor the execution of guidelines thus formulated. Training sessions are also indicated, to provide training for medical officers on administration of ECT and an ECT competency certificate could be issued for those trained in administration of ECT. Reevaluation should be considered six months after introduction of such guidelines, in order to explore the efficacy of such recommendations and changes.

\section{Declaration of interest}

None declared 
DMA Dahanayake, YM Rohanachandra, ARK Dissanayake, H Gambheera, National Institute of Mental Health, Angoda, Sri Lanka

Corresponding author: DMA Dahanayake

Email: dulangid@yahoo.com

\section{References}

1. Jha A. Electroconvulsive therapy and other physical therapies. In: Stein G, Wilkinson G (eds.) Seminars in general adult psychiatry. London: Gaskell 2007; 113-28.

2. Carpenter JS. The history of mental health care in Sri Lanka. Colombo: Marga 1987.

3. Ulhaq S, Nnatu I, Kelly S, Sooky R. Compliance with ECT NICE guidance by the John Connolly ECT clinic January 2010 - July 2010. Psychiatr Danub 2011; Suppl 1: 99-103.

4. O’Connor DW, Gardner B, Presnell I, et al. Continuationmaintenance electroconvulsive therapy: quality standards in 3 Australian aged psychiatry services. J ECT 2010; 26(2): 95-7.

5. Ranasinghe P. Patients' experience and attitudes towards Electroconvulsive Therapy - a descriptive study. MD thesis, Post Graduate Institute of Medicine, University of Colombo. 2003.

6. Scott AIF. The ECT hand book. $2^{\text {nd }}$ ed. Glasgow: Bell \& Brain 2005.

7. Royal Australian and New Zealand College of Psychiatrists. Guidelines on the administration of ECT, 1999. Available at:https://www.ranzcp.org/Publications/ Statements-Guidelines.aspx\#therapeutics-nonpharmaco logical (accessed January 2012)

8. Mankad MV, Beyer JL, Weiner RD, Krystal AD. Clinical Manual of electroconvulsive therapy. Washington: American Psychiatric Publishing Inc 2010.

9. Cowen P, Harrison P and Burns T. Shorter Oxford textbook of psychiatry. $6^{\text {th }}$ ed. Oxford: Oxford University Press 2012.

10. Mental Diseases Ordinance of Sri Lanka, 1873. Available at: www.commonlii.org/lk/legis/consol_act/md559196.pdf (accessed October 2014). 